\title{
Review Article \\ Capsule Endoscopy for Crohn's Disease: Current Status of Diagnosis and Management
}

\author{
Dong-Hoon Yang, ${ }^{1}$ Bora Keum, ${ }^{2}$ and Yoon Tae Jeen ${ }^{2}$ \\ ${ }^{1}$ Department of Gastroenterology, Asan Medical Center, University of Ulsan College of Medicine, Seoul, Republic of Korea \\ ${ }^{2}$ Department of Internal Medicine, Korea University Anam Hospital, Korea University College of Medicine, Seoul, Republic of Korea \\ Correspondence should be addressed to Yoon Tae Jeen; ytjeen@korea.ac.kr
}

Received 30 June 2015; Revised 7 September 2015; Accepted 10 September 2015

Academic Editor: Myung-Gyu Choi

Copyright (c) 2016 Dong-Hoon Yang et al. This is an open access article distributed under the Creative Commons Attribution License, which permits unrestricted use, distribution, and reproduction in any medium, provided the original work is properly cited.

Crohn's disease (CD) is an idiopathic inflammatory bowel disease involving the small and/or large intestine. More than 50\% of Western CD patients and up to $88 \%$ of Asian CD patients may have small intestinal involvement. Video capsule endoscopy (VCE) has a higher diagnostic yield than small bowel barium radiography and computed tomography enterography for the detection of small intestinal involvement of CD. VCE also provides diagnostic yields comparable to magnetic resonance- (MR-) based enterography or enteroclysis and may have several advantages over MR-based tests for the detection of early small intestinal lesions. Several studies have suggested the use of VCE-based disease activity scoring systems to evaluate small intestinal mucosal disease activity, although their clinical relevance needs to be further studied. A possible indication for VCE is recurrence monitoring after complete surgical excision of CD-involved segments but its usefulness and efficacy compared with conventional endoscopy should be evaluated. The capsule retention rate ranges from 0 to $5.4 \%$ in suspected CD patients and from 0 to $13.2 \%$ in established CD patients. If VCE is necessary, significant small bowel stricture should be ruled out before VCE by performing a patency capsule study and/or small bowel radiological study in suspected or established CD patients.

\section{Introduction}

Crohn's disease $(\mathrm{CD})$ is a chronic, idiopathic inflammatory bowel disease (IBD) that mainly involves the small and/or large intestines. According to population-based epidemiologic studies, more than $50 \%$ of Western CD patients [1-5] and $77-87.7 \%$ of Asian CD patients have small bowel involvement at diagnosis [6-8]. Therefore, evaluation of the small and large intestine is essential for the diagnosis of $\mathrm{CD}$, but there are no known pathognomonic features in endoscopic and radiologic studies.

Given that mucosal healing is considered a target of CD treatment in the biologic era [9], the endoscopic evaluation of the intestinal mucosa is crucial for assessing the treatment response and establishing a treatment strategy. In the past, small bowel follow-through (SBFT), enteroclysis (EC), and surgical exploration were the only methods for evaluating the status of the small intestine in CD patients. With technological advances, computed tomography- (CT-) based imaging protocols, such as CT enterography (CTE)/CT enteroclysis (CTEC), and magnetic resonance- (MR-) based imaging protocols, such as MR enterography (MRE)/MR enteroclysis (MREC), have become available for the radiological investigation of small intestinal lesions. However, none of these radiologic modalities can provide direct visualization of the small bowel mucosa and, thus, all carry an intrinsic limitation in the precise assessment of mucosal healing.

The introduction of wireless video capsule endoscopy (VCE) and device-assisted enteroscopy has enabled the direct visualization of the small intestinal mucosa. Because of the reduced invasiveness of VCE compared with device-assisted enteroscopy, $\mathrm{VCE}$ is more suitable for the diagnosis of $\mathrm{CD}$ and the assessment of the treatment response, unless the patients have suspected intestinal strictures that can potentially cause 
capsule retention. Our present review is focused on the clinical usefulness and application of VCE in CD.

\section{Diagnostic Yield and Performance of VCE in CD}

CD frequently involves the terminal ileum which usually can be evaluated using ileocolonoscopy. However, the involvement of small intestine more proximal to terminal ileum is common in CD and often affects the patients' clinical manifestation and outcomes. Small bowel barium radiography, including SBFT and EC, was a traditional diagnostic modality for evaluating the entire small intestine but has been progressively substituted by cross-sectional radiologic tests such as CTE/CTEC and MRE/MREC for the evaluation of the patients with suspected or established small intestinal CD. However, given that the VCE can visualize the intestinal mucosa directly, VCE is more likely to detect earlier lesions or subtle mucosal lesions than small intestinal radiologic studies including small bowel barium radiography, CTE, and MRE. Many investigators have compared the diagnostic yield of VCE with that of other radiologic studies in the patients with suspected or established CD.

Comparing with small bowel barium radiography, such as SBFT or EC, VCE showed better diagnostic yield for the patients having suspected CD (Table 1). The reported diagnostic yield of VCE ranged from $49 \%$ to $77 \%$, whereas those of SBFT and EC ranged from $21 \%$ to $67 \%$ [10-13] and from $12 \%$ to $36 \%$ [14-16], respectively. Although the number of participants in each study was small, meta-analyses reported again that VCE is superior to small bowel barium radiography in terms of diagnostic yield [17-19].

The reported diagnostic yield of VCE was higher than that of CTE/CTEC in most previous studies (Table 2). The diagnostic yield was $61 \%$ for VCE and $29 \%$ for CTEC according to a prospective comparison of VCE and CTEC for the diagnosis of small bowel involvement in established CD patients [20]. The diagnostic yields of VCE and CTE in three studies of suspected or established CD patients ranged from 30\% to $77 \%$ and from $33 \%$ to $53 \%$, respectively $[12,21,22]$. Two of these studies reported a better diagnostic yield of VCE compared with CTE $[12,21]$ but the other study, using ileocolonoscopic findings and surgery as the gold standards, reported a similar diagnostic yield of the two modalities for terminal ileal CD [22]. However, although the diagnostic yield was similar between VCE and CTE in that larger study (30\% for VCE and $33 \%$ for CTE), VCE showed higher sensitivity and specificity for the detection of terminal ileal lesions than CTE (sensitivity, $100 \%$ for VCE versus $76 \%$ for CTE; specificity, $91 \%$ for VCE versus $85 \%$ for CTE) [22]. On the other hand, another study reported that the sensitivity of VCE was similar to that of CTE but that the specificity was inferior to that of CTE [23]. The sensitivity and specificity of VCE and CTE/CTEC may result from different definitions of positive findings between two modalities, but this study concluded the diagnosis of small intestinal CD based on the consensus panel of the coinvestigators instead of specifying findings for diagnosis of small intestinal involvement. Considering the nature of each diagnostic modality and the limited number of participants in most studies, if the proportion of CD patients having subtle small intestinal lesions was small, such studies could not show the superiority of VCE in the diagnostic yield comparing with CTE/CTEC. Although a few studies did not show the superiority in diagnostic yield, recent meta-analyses concluded that VCE had superior diagnostic yield in the small bowel CD compared with CTE/CTEC.

Several prospective studies reported the diagnostic yield or performance of VCE and MRE/MREC (Table 3) and a recent meta-analysis that included five prospective studies reported that the effectiveness of VCE and MRE/MREC in the diagnosis of small bowel CD was comparable [18]. In spite of similar diagnostic yields between two modalities, VCE showed better sensitivity than MRE/MREC in several studies. One study suggested MREC was superior to VCE in the diagnostic performance. However, the diagnostic performance of MREC in all participants (including 34\% of stenotic CD) was compared with the diagnostic performance of VCE in the nonstenotic CD [24]. Therefore, this study is not suitable to conclude the difference in the diagnostic performance between VCE and MREC for the nonstenotic CD patients.

Four prospective studies [21, 25-27] and two abstracts $[28,29]$ have compared the diagnostic yield of VCE and ileocolonoscopy in CD patients (Table 4). According to a recent meta-analysis that included these six studies, the weighted incremental diagnostic yield of VCE compared with ileocolonoscopy was 0.12 (95\% confidence interval [CI], 0.00$0.23 ; P=0.04$ ). Because push enteroscopy cannot effectively shorten the bowel, the depth of insertion is usually less than $120 \mathrm{~cm}$ from the Treitz ligament, even with an overtube [30, 31]. VCE and push enteroscopy in small bowel CD patients have been described in only one prospective study [15] and one abstract [28]. A meta-analysis of these two studies showed that the weighted incremental diagnostic yield of VCE compared with push enteroscopy was 0.43 (95\% CI, $0.32-0.53 ; P<0.00001)[18]$.

\section{Clinical Application of VCE in CD}

3.1. Diagnosis of CD. According to the previous studies, the diagnostic yield of VCE is better than that of SBFT or CTE/ CTEC and comparable to MRE/MREC. However, before performing VCE, clinician should take into account several things. First, diagnostic yield does not mean diagnostic accuracy. The diagnostic yield does not mean the number of tests with "diagnostic" findings among the total number of tests but the number of tests with abnormal findings among the total number of tests. Moreover, there are no available standardized VCE findings for diagnostic or specific to CD. Therefore, a high diagnostic yield in a certain study does not indicate high diagnostic accuracy and the diagnostic yield can also be influenced by the study participants' likelihood of having CD. In a previous study, for example, the yield of VCE for the evaluation of abdominal pain and/or diarrhea lasting longer than 6 months was low [35], but 12 of 17 patients with nondiagnostic ileocolonoscopic and radiologic studies, who had abdominal pain, diarrhea, anemia, and weight loss for 6.3 years on average, showed abnormal VCE findings compatible with CD [36]. The international conference on capsule 


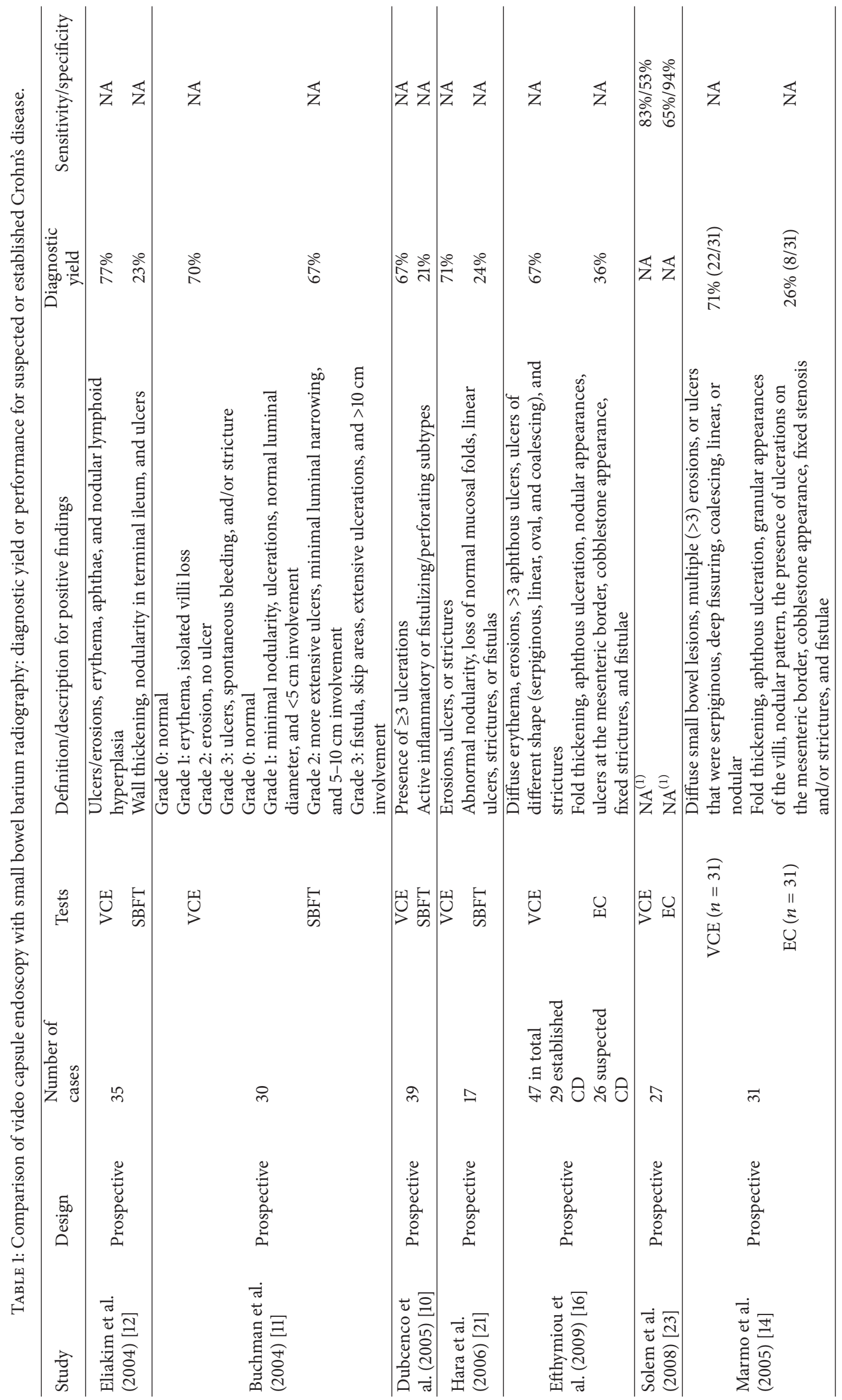




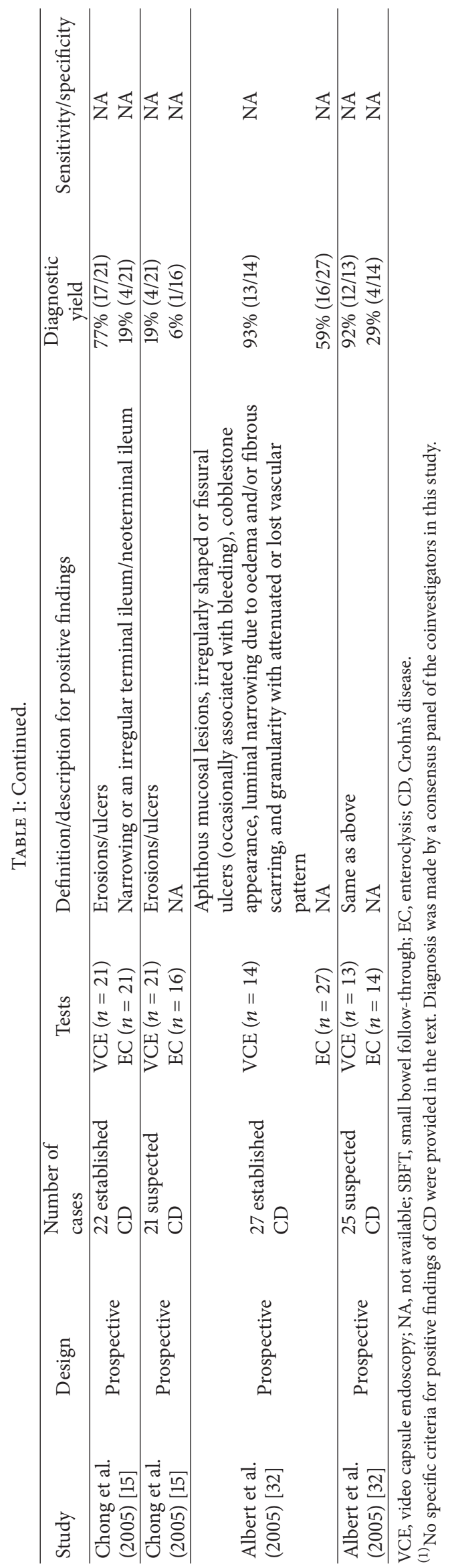




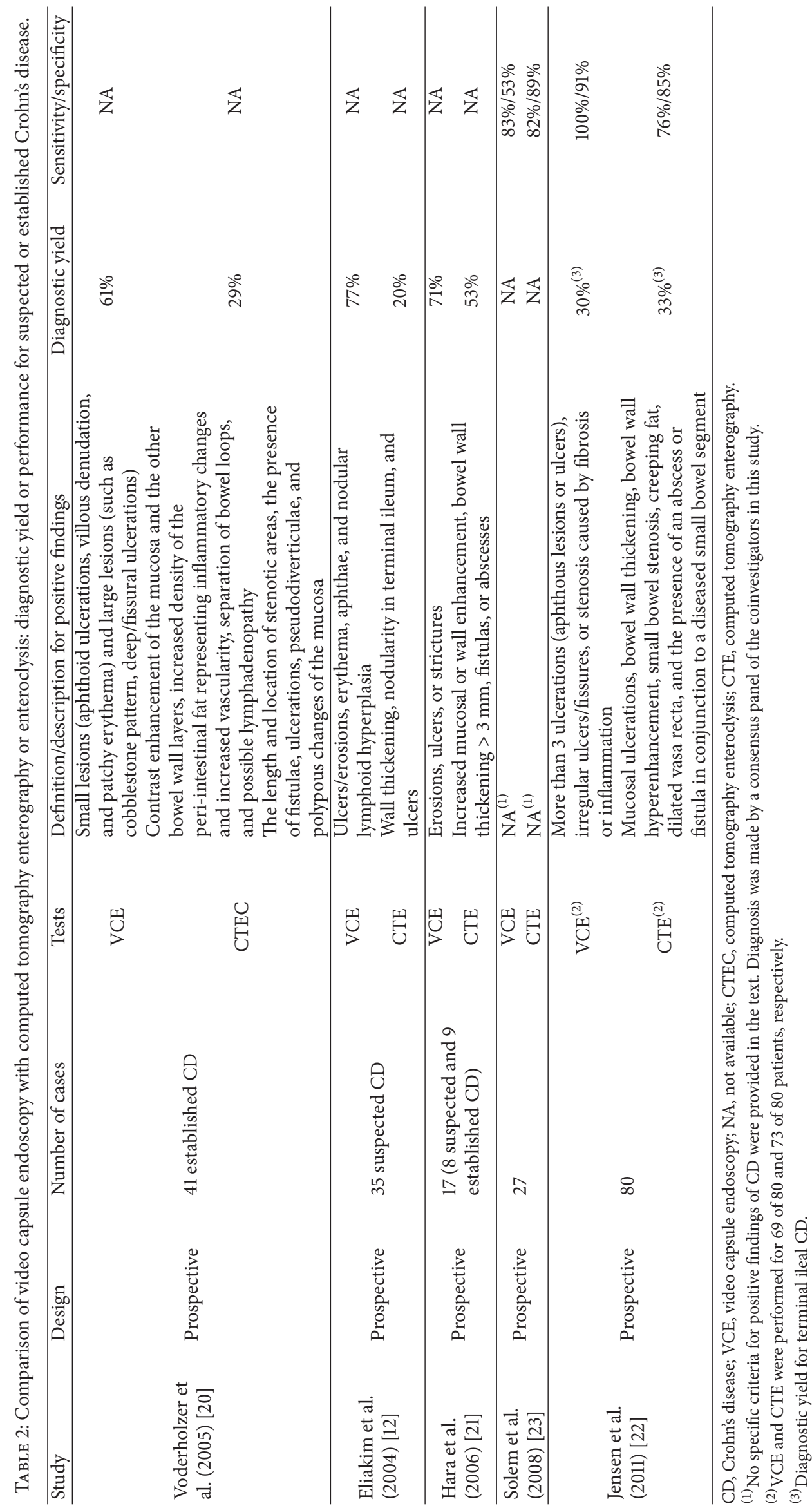




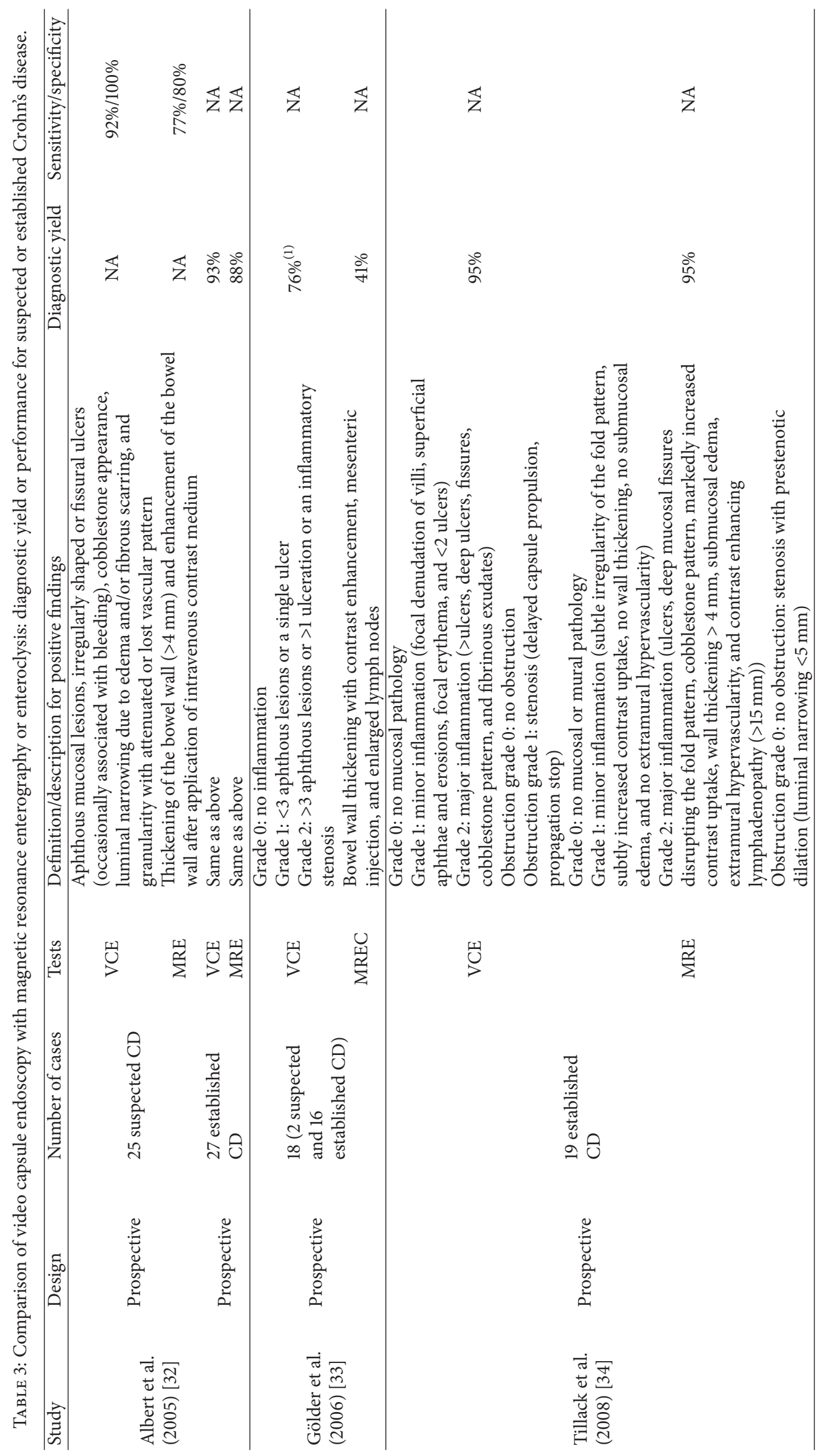




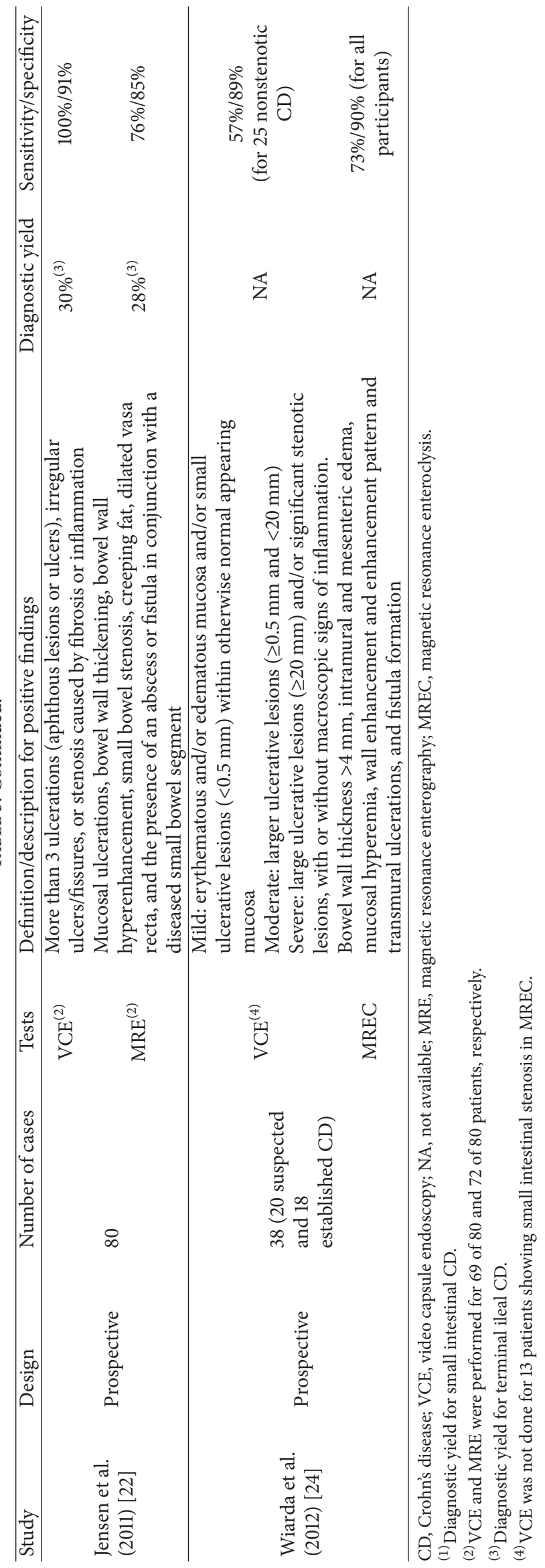


TABLE 4: Comparison of video capsule endoscopy with ileocolonoscopy or push enteroscopy: diagnostic yield or performance for suspected or established Crohn's disease.

\begin{tabular}{|c|c|c|c|c|c|}
\hline Study & Design & Number of cases & Tests & $\begin{array}{l}\text { Definition/description for } \\
\text { positive findings }\end{array}$ & Diagnostic yield \\
\hline \multirow{2}{*}{$\begin{array}{l}\text { Bloom et al. } \\
(2003)[29]\end{array}$} & \multirow{2}{*}{ Prospective } & \multirow{2}{*}{16} & VCE & NA & $56 \%$ \\
\hline & & & $\mathrm{IL}$ & NA & $50 \%$ \\
\hline \multirow[t]{2}{*}{$\begin{array}{l}\text { Bourreille et } \\
\text { al. (2006) } \\
{[25]}\end{array}$} & \multirow[t]{2}{*}{ Prospective } & \multirow[t]{2}{*}{$\begin{array}{l}31 \text { (for postoperative } \\
\text { evaluation) }\end{array}$} & VCE & $\begin{array}{l}\text { Erythema, villous denudation, } \\
\text { erosion, and ulceration } \\
\text { (Rutgeerts score } \geq 1 \text { for the } \\
\text { recurrence at the neoterminal } \\
\text { ileum) }\end{array}$ & $\begin{array}{l}42-55 \% \text { for neoterminal } \\
\text { ileum, } 66-72 \% \text { for entire } \\
\text { small bowel }\end{array}$ \\
\hline & & & IL & Rutgeerts score $\geq 1$ & $61 \%$ \\
\hline \multirow{2}{*}{$\begin{array}{l}\text { Hara et al. } \\
(2006)[21]\end{array}$} & \multirow{2}{*}{ Prospective } & \multirow{2}{*}{$\begin{array}{l}17 \text { ( } 8 \text { suspected and } 9 \\
\text { established CD) }\end{array}$} & VCE & Erosions, ulcers, or strictures & $71 \%$ \\
\hline & & & $\mathrm{IL}$ & Erosions, ulcers, or strictures & $65 \%$ \\
\hline \multirow[t]{2}{*}{$\begin{array}{l}\text { Biancone et } \\
\text { al. }(2007) \\
{[26]}\end{array}$} & \multirow[t]{2}{*}{ Prospective } & \multirow[t]{2}{*}{$\begin{array}{l}17 \text { (for postoperative } \\
\text { evaluation) }\end{array}$} & VCE & $\begin{array}{l}\text { Separate detection of ulcers, } \\
\text { strictures, or stenosis in the } \\
\text { neoterminal ileum and/or } \\
\text { anastomosis }\end{array}$ & $94 \%$ \\
\hline & & & IL & Rutgeerts score $\geq 1$ & $94 \%$ \\
\hline \multirow{2}{*}{$\begin{array}{l}\text { Beltrán et al. } \\
\text { (2007) [27] }\end{array}$} & \multirow{2}{*}{ Prospective } & \multirow{2}{*}{$\begin{array}{l}24 \text { (for postoperative } \\
\text { evaluation) }\end{array}$} & VCE & $\begin{array}{l}\text { Aphthoid ulcerations, small } \\
\text { ulcer, cobblestone pattern, and } \\
\text { deep/fissural ulcerations }\end{array}$ & $62 \%(15 / 21)$ \\
\hline & & & IL & $\begin{array}{l}\text { Aphthoid ulcerations, small } \\
\text { ulcer, cobblestone pattern, and } \\
\text { deep/fissural ulcerations }\end{array}$ & $25 \%(6 / 21)$ \\
\hline \multirow{2}{*}{$\begin{array}{l}\text { Chong et al. } \\
\text { (2005) [15] }\end{array}$} & \multirow{2}{*}{ Prospective } & \multirow{2}{*}{22 established CD } & VCE & Erosions/ulcers & $77 \%$ \\
\hline & & & PE & NA & $14 \%$ \\
\hline \multirow{2}{*}{$\begin{array}{l}\text { Chong et al. } \\
\text { (2005) [15] }\end{array}$} & \multirow{2}{*}{ Prospective } & \multirow{2}{*}{21 suspected CD } & VCE & Erosions/ulcers & $19 \%$ \\
\hline & & & $\mathrm{PE}$ & NA & 0 \\
\hline
\end{tabular}

CD, Crohn's disease; VCE, video capsule endoscopy; IL, ileocolonoscopy; PE, push enteroscopy.

endoscopy (ICCE) recommended that VCE should be considered for the patients with suspected CD if they present with typical symptoms plus either extraintestinal manifestations, abnormal inflammatory markers, or abnormal small bowel imaging [37], and a retrospective study showed that the $57.9 \%$ of patients fulfilling two criteria and $77.8 \%$ of patient fulfilling 3 or more criteria showed significant VCE findings but only $17.8 \%$ of patients showed significant VCE findings when they did not meet ICCE criteria [38].

Second, suspected and established CD is the major risk factor of capsule retention and thus, the presence of stricture should be assessed before performing VCE. According to a systematic review, the pooled capsule retention rate for all indications was $1.4 \%$ and the retention rate for indications of $\mathrm{CD}$ was $2.6 \%$. The retention rate in suspected $\mathrm{CD}$ patients and established CD patients ranged from $0 \%$ to $5.4 \%$ and from $0 \%$ to $13.2 \%$, respectively $[11,13,14,20,36,39-43]$. Six prospective studies reported that VCE was successfully completed without retention in all patients with suspected intestinal stricture after passage of an intact patency capsule [44-49]. A retrospective study comparing patency capsule with radiologic studies (10 CT, 29 CTE, 9 MRE, and 2 SBFT) for the detection of significant strictures in order to avoid capsule retention reported that both patency capsule and radiologic studies showed equivalently high sensitivity and negative predictive value for the detection of significant intestinal strictures, defined as strictures that require surgery due to bowel obstruction or capsule retention [50]. Based on these reports, a recent guideline for VCE has recommended that significant small bowel strictures be ruled out before VCE by performing a patency capsule study and/or small bowel radiological study in suspected or established CD patients [18].

Third, the clinical impact of VCE on the management of suspected or established CD patients should be considered. Several retrospective studies suggested that VCE led to a definitive diagnosis of $\mathrm{CD}$, changed the management of $\mathrm{CD}$, or had a potential impact on the prognosis prediction of $\mathrm{CD}$ [51-56]. In a small prospective pediatric study, VCE reclassified 2 of 4 ulcerative colitis or indeterminate colitis patients and 8 of 10 suspected IBD patients as small bowel CD [57]. In another pediatric study, $50 \%$ of ulcerative colitis or unclassified IBD patients were finally diagnosed with CD and, more importantly, $94 \%$ of the suspected IBD patients were finally diagnosed as not having IBD [58]. The high negative predictive value $(96 \%-100 \%)$ of VCE in other studies $[22,39,59]$ suggests that VCE may have a significant advantage in the exclusion of the small bowel involvement of CD and IBD.

Given the risk of capsule retention, the absence of a standardized definition or description of VCE findings in small intestinal $\mathrm{CD}$, and the lack of data related to the clinical 
impact or optimal indications of VCE, the role of VCE in the diagnosis of CD is still controversial and needs to be established more in detail. The second European evidencebased consensus on the diagnosis and management of CD stated that VCE can be used as a first-line test after exclusion of significant stenosis using a patency capsule or as a secondline test in patients in whom the clinical suspicion for $\mathrm{CD}$ remains high despite negative evaluations with ileocolonoscopy and radiologic examination [60]. The recent Korean guidelines for VCE in CD suggested that "in wellselected patients with a high suspicion of CD," VCE is useful for diagnosing CD after negative ileocolonoscopy and small bowel radiologic examination [18]. Recently, the European Society of Gastrointestinal Endoscopy (ESGE) suggested different diagnostic recommendations for suspected CD and established CD [61]. In patients with suspected CD and negative ileocolonoscopy findings, the ESGE recommends VCE as the initial diagnostic modality for investigating the small bowel in the absence of obstructive symptoms or known stenosis [61]. On the other hand, in patients with established $\mathrm{CD}$ based on ileocolonoscopy findings, if the cross-sectional imaging tests were unremarkable or nondiagnostic and it is believed that VCE would influence patient management, the ESGE recommended VCE as a subsequent test [61].

\subsection{Assessment of Disease Activity. Mucosal healing has been} reported to be associated with better long-term prognosis in $\mathrm{CD}$ and has recently been considered to be a new target of CD treatment. VCE is useful to assess the disease activity and treatment response in small intestinal CD by providing information about the status of the small intestinal mucosa. Two VCE-based scoring systems have been suggested to quantify the extent of small intestinal disease in CD: the Lewis score and the Capsule Endoscopy Crohn's Disease Activity Index (CECDAI). The Lewis score uses three parametersvillous edema, ulceration, and stenosis-and the score for each parameter is weighted based on the extent and severity [62]. The whole small intestine observed by VCE is divided into three tertiles; the levels of villous edema and ulceration are scored for each tertile but stenosis is graded in the whole study, independent of the individual tertiles. When the scores were matched with the global assessment of mucosal disease activity, Lewis scores <135, 135-790, and $>790$ were categorized as normal, mild-to-moderate, and severe mucosal disease activity, respectively.

The other VCE-based CD disease activity assessment system, CECDAI [63], divides the small intestine into proximal and distal segments and uses different weights for three parameters: inflammation, extent of disease, and stricture. The final score is the sum of the proximal and distal segmental numbers and ranges from 0 (normal study) to 36 (severe disease). The interobserver agreement for the CECDAI score was excellent, with a Kappa value of 0.867. Good interobserver agreement of CECDAI was also validated in a prospective multicenter study of isolated small intestinal CD patients, but this study failed to show any significant correlation between CECDAI and the Crohn's Disease Activity Index (CDAI) or the Inflammatory Bowel Disease Quality of Life Questionnaire (IBDQ) [64]. In a retrospective study, the
Lewis score showed a statistically significant correlation with CECDAI $(r=0.6324)$, but the Lewis score showed a better correlation with fecal calprotectin levels than CECDAI in CD patients with fecal calprotectin $<100 \mu \mathrm{g} / \mathrm{g}$ [65].

On the other hand, another retrospective multicenter study showed a poor correlation between fecal calprotectin and the Lewis score in CD patients, and exclusion of isolated colonic CD did not significantly improve their correlation. Therefore, the correlation between fecal calprotectin and the Lewis score or CECDAI is still controversial and should be investigated further. A recent retrospective study reported that therapeutic change was recommended in $14.5 \%, 48.1 \%$, and $87.1 \%$ of patients with no small intestinal inflammation (Lewis score $<135$ ), mild small intestinal inflammation (Lewis score, 135-790), and moderate-to-severe small intestinal inflammation (Lewis score $>790$ ), respectively [55]. However, little is known about the roles of VCE-based disease activity indexes as indicators of treatment alterations or prognosis predictors. Further studies should be performed to determine the clinical implication of these indexes in the management of CD patients with small intestinal involvement.

\subsection{Assessment of Postoperative Recurrence. Postoperative} recurrence is quite common in $\mathrm{CD}$ and endoscopic recurrence usually precedes clinical recurrence. Therefore, postoperative surveillance of recurrence is an important issue in the management of CD. According to a prospective study that compared the usefulness of VCE and ileocolonoscopy as tools for monitoring postoperative $\mathrm{CD}$ recurrence, $\mathrm{VCE}$ seems not to be superior to ileocolonoscopy in the detection of endoscopic recurrence [25]. However, in that study, the investigators assessed the findings just around the anastomosis, which can be easily assessed by ileocolonoscopy in most postoperative cases. Another study suggested that VCE is more effective in the evaluation of recurrence after surgery for $\mathrm{CD}$ and is better tolerated than ileocolonoscopy [27]. Other studies also supported the usefulness of VCE as a noninvasive monitoring tool for postoperative recurrence of CD $[26,66]$, but further prospective studies with large number of patients are necessary to confirm the clinical usefulness of VCE for the detection of the postoperative recurrence of CD.

\section{Conclusion}

The diagnostic accuracy of VCE is superior to that of SBFT and CTE/CTEC and comparable to that of MRE in the diagnosis of CD. VCE is also more sensitive for the detection of subtle mucosal inflammation than MRE. Therefore, potential benefits from VCE can be anticipated in the diagnosis, management, and surveillance of postoperative recurrence CD. The therapeutic impact of VCE in CD could be derived from its accurate diagnosis and information on the extent of disease or disease activity, and several retrospective studies have reported that $\mathrm{CD}$ management changed after VCE in $53 \%-61.6 \%$ of patients $[52,54,55]$. VCE has a higher negative predictive value for the diagnosis of small intestinal CD than other modalities [22] and clinical and serologic disease activity indexes of CD show no or weak correlation with endoscopically assessed mucosal disease activities [64, 
67, 68]. Therefore, even a normal VCE finding may be helpful for the management of symptomatic CD patients because it suggests a noninflammatory origin of symptoms such as those of irritable bowel syndrome. However, clinical experience with VCE for the diagnosis and management of CD is still limited despite the advantages of VCE over other modalities. The risk of capsule retention, lack of evidence on the clinical benefit, and lack of established indications for VCE in CD may limit the widespread use of VCE in clinical practice for suspected or established CD patients. Further studies are required to minimize the risk of capsule retention, to assess the clinical benefits and impact of VCE, and to establish the indications for VCE in CD.

\section{Conflict of Interests}

The authors declare that there is no conflict of interests regarding the publication of this paper.

\section{References}

[1] I. Vind, L. Riis, T. Jess et al., "Increasing incidences of inflammatory bowel disease and decreasing surgery rates in Copenhagen City and County, 2003-2005: a population-based study from the Danish Crohn colitis database," The American Journal of Gastroenterology, vol. 101, no. 6, pp. 1274-1282, 2006.

[2] I. C. Solberg, M. H. Vatn, O. Høie et al., "Clinical course in Crohn's disease: results of a Norwegian population-based tenyear follow-up study," Clinical Gastroenterology and Hepatology, vol. 5, no. 12, pp. 1430-1438, 2007.

[3] C. Gower-Rousseau, F. Vasseur, M. Fumery et al., "Epidemiology of inflammatory bowel diseases: new insights from a French population-based registry (EPIMAD)," Digestive and Liver Disease, vol. 45, no. 2, pp. 89-94, 2013.

[4] V. J. A. A. Nuij, Z. Zelinkova, M. C. M. Rijk et al., "Phenotype of inflammatory bowel disease at diagnosis in the Netherlands: a population-based inception cohort study (the Delta Cohort)," Inflammatory Bowel Diseases, vol. 19, no. 10, pp. 2215-2222, 2013.

[5] D. Sjöberg, T. Holmström, M. Larsson et al., "Incidence and clinical course of Crohn's disease during the first year-results from the IBD Cohort of the Uppsala Region (ICURE) of Sweden 2005-2009," Journal of Crohn's and Colitis, vol. 8, no. 3, pp. 215222, 2014.

[6] S.-K. Yang, S. Yun, J.-H. Kim et al., "Epidemiology of inflammatory bowel disease in the Songpa-Kangdong district, Seoul, Korea, 1986-2005: a KASID study," Inflammatory Bowel Diseases, vol. 14, no. 4, pp. 542-549, 2008.

[7] Y. Niv, G. Abuksis, and G. M. Fraser, "Epidemiology of Crohn's disease in Israel: a survey of Israeli kibbutz settlements," The American Journal of Gastroenterology, vol. 94, no. 10, pp. 29612965, 1999.

[8] H. Abdul-Baki, I. ElHajj, L. M. N. El-Zahabi et al., "Clinical epidemiology of inflammatory bowel disease in Lebanon," Inflammatory Bowel Diseases, vol. 13, no. 4, pp. 475-480, 2007.

[9] G. Bouguen, B. G. Levesque, B. G. Feagan et al., "Treat to target: a proposed new paradigm for the management of Crohn's disease," Clinical Gastroenterology and Hepatology, vol. 13, no. 6, pp. 1042.e2-1050.e2, 2015.

[10] E. Dubcenco, K. N. Jeejeebhoy, R. Petroniene et al., "Capsule endoscopy findings in patients with established and suspected small-bowel Crohn's disease: correlation with radiologic, endoscopic, and histologic findings," Gastrointestinal Endoscopy, vol. 62, no. 4, pp. 538-544, 2005.

[11] A. L. Buchman, F. H. Miller, A. Wallin, A. A. Chowdhry, and C. Ahn, "Videocapsule endoscopy versus barium contrast studies for the diagnosis of Crohn's disease recurrence involving the small intestine," American Journal of Gastroenterology, vol. 99, no. 11, pp. 2171-2177, 2004.

[12] R. Eliakim, A. Suissa, K. Yassin, D. Katz, and D. Fischer, "Wireless capsule video endoscopy compared to barium followthrough and computerised tomography in patients with suspected Crohn's disease-final report," Digestive and Liver Disease, vol. 36, no. 8, pp. 519-522, 2004.

[13] R. Eliakim, D. Fischer, A. Suissa et al., "Wireless capsule video endoscopy is a superior diagnostic tool in comparison to barium follow-through and computerized tomography in patients with suspected Crohn's disease," European Journal of Gastroenterology and Hepatology, vol. 15, no. 4, pp. 363-367, 2003.

[14] R. Marmo, G. Rotondano, R. Piscopo et al., "Capsule endoscopy versus enteroclysis in the detection of small-bowel involvement in Crohn's disease: a prospective trial," Clinical Gastroenterology and Hepatology, vol. 3, no. 8, pp. 772-776, 2005.

[15] A. K. H. Chong, A. Taylor, A. Miller, O. Hennessy, W. Connell, and P. Desmond, "Capsule endoscopy vs. push enteroscopy and enteroclysis in suspected small-bowel Crohn's disease," Gastrointestinal Endoscopy, vol. 61, no. 2, pp. 255-261, 2005.

[16] A. Efthymiou, N. Viazis, J. Vlachogiannakos et al., "Wireless capsule endoscopy versus enteroclysis in the diagnosis of smallbowel Crohn's disease," European Journal of Gastroenterology and Hepatology, vol. 21, no. 8, pp. 866-871, 2009.

[17] S. L. Triester, J. A. Leighton, G. I. Leontiadis et al., "A metaanalysis of the yield of capsule endoscopy compared to other diagnostic modalities in patients with non-stricturing small bowel Crohn's disease," American Journal of Gastroenterology, vol. 101, no. 5, pp. 954-964, 2006.

[18] S. K. Park, B. D. Ye, K. O. Kim et al., "Guidelines for video capsule endoscopy: emphasis on Crohn's disease," Clinical Endoscopy, vol. 48, no. 2, pp. 128-135, 2015.

[19] P. M. Dionisio, S. R. Gurudu, J. A. Leighton et al., "Capsule endoscopy has a significantly higher diagnostic yield in patients with suspected and established small-bowel crohn's disease: a meta-analysis," The American Journal of Gastroenterology, vol. 105, no. 6, pp. 1240-1248, 2010.

[20] W. A. Voderholzer, J. Beinhoelzl, P. Rogalla et al., "Small bowel involvement in Crohn's disease: a prospective comparison of wireless capsule endoscopy and computed tomography enteroclysis," Gut, vol. 54, no. 3, pp. 369-373, 2005.

[21] A. K. Hara, J. A. Leighton, R. I. Heigh et al., "Crohn disease of the small bowel: preliminary comparison among CT enterography, capsule endoscopy, small-bowel follow-through, and ileoscopy," Radiology, vol. 238, no. 1, pp. 128-134, 2006.

[22] M. D. Jensen, T. Nathan, S. R. Rafaelsen, and J. Kjeldsen, "Diagnostic accuracy of capsule endoscopy for small bowel Crohn's disease is superior to that of MR enterography or CT enterography," Clinical Gastroenterology and Hepatology, vol. 9, no. 2, pp. 124-129, 2011.

[23] C. A. Solem, E. V. Loftus Jr., J. G. Fletcher et al., "Smallbowel imaging in Crohn's disease: a prospective, blinded, 4-way comparison trial," Gastrointestinal Endoscopy, vol. 68, no. 2, pp. 255-266, 2008. 
[24] B. M. Wiarda, P. B. F. Mensink, D. G. N. Heine et al., "Small bowel Crohn's disease: MR enteroclysis and capsule endoscopy compared to balloon-assisted enteroscopy," Abdominal Imaging, vol. 37, no. 3, pp. 397-403, 2012.

[25] A. Bourreille, M. Jarry, P. N. D’Halluin et al., "Wireless capsule endoscopy versus ileocolonoscopy for the diagnosis of postoperative recurrence of Crohn's disease: a prospective study," Gut, vol. 55, no. 7, pp. 978-983, 2006.

[26] L. Biancone, E. Calabrese, C. Petruzziello et al., "Wireless capsule endoscopy and small intestine contrast ultrasonography in recurrence of Crohn's disease," Inflammatory Bowel Diseases, vol. 13, no. 10, pp. 1256-1265, 2007.

[27] V. P. Beltrán, P. Nos, G. Bastida et al., "Evaluation of postsurgical recurrence in Crohn's disease: a new indication for capsule endoscopy?" Gastrointestinal Endoscopy, vol. 66, no. 3, pp. 533540, 2007.

[28] E. Toth, P. Almqvist, and C. Benoni, "Endoscopic diagnosis of small bowel Crohn's disease: a prospective, comparative study of capsule endoscopy, barium enterography, push enteroscopy and ileo-colonoscopy," Gut, vol. 54, article A50, 2005.

[29] P. D. Bloom, M. D. Rosenberg, S. D. Klein et al., "Wireless capsule endoscopy (CE) is more informative than ileoscopy and SBFT for the evaluation of the small intestine (SI) in patients with known or suspected Crohn's disease," Gastroenterology, vol. 124, no. 4, pp. A203-A204, 2003.

[30] A. C. F. Taylor, R. Y. M. Chen, and P. V. Desmond, "Use of an overtube for enteroscopy-does it increase depth of insertion? A prospective study of enteroscopy with and without an overtube," Endoscopy, vol. 33, no. 3, pp. 227-230, 2001.

[31] C. Benz, R. Jakobs, and J. F. Riemann, "Do we need the overtube for push-enteroscopy?” Endoscopy, vol. 33, no. 8, pp. 658-661, 2001.

[32] J. G. Albert, F. Martiny, A. Krummenerl et al., "Diagnosis of small bowel Crohn's disease: a prospective comparison of capsule endoscopy with magnetic resonance imaging and fluoroscopic enteroclysis," Gut, vol. 54, no. 12, pp. 1721-1727, 2005.

[33] S. K. Gölder, A. G. Schreyer, E. Endlicher et al., "Comparison of capsule endoscopy and magnetic resonance (MR) enteroclysis in suspected small bowel disease," International Journal of Colorectal Disease, vol. 21, no. 2, pp. 97-104, 2006.

[34] C. Tillack, J. Seiderer, S. Brand et al., "Correlation of magnetic resonance enteroclysis (MRE) and wireless capsule endoscopy (CE) in the diagnosis of small bowel lesions in Crohn's disease," Inflammatory Bowel Diseases, vol. 14, no. 9, pp. 1219-1228, 2008.

[35] L. C. Fry, E. J. Carey, A. D. Shiff et al., "The yield of capsule endoscopy in patients with abdominal pain or diarrhea," Endoscopy, vol. 38, no. 5, pp. 498-502, 2006.

[36] Z. Fireman, E. Mahajna, E. Broide et al., "Diagnosing small bowel Crohn's disease with wireless capsule endoscopy," Gut, vol. 52, no. 3, pp. 390-392, 2003.

[37] K. Mergener, T. Ponchon, I. Gralnek et al., "Literature review and recommendations for clinical application of small-bowel capsule endoscopy, based on a panel discussion by international experts," Endoscopy, vol. 39, no. 10, pp. 895-909, 2007.

[38] B. Rosa, M. J. Moreira, A. Rebelo, and J. Cotter, "Lewis Score: a useful clinical tool for patients with suspected Crohn's disease submitted to capsule endoscopy," Journal of Crohn's and Colitis, vol. 6, no. 6, pp. 692-697, 2012.

[39] W. S. Mow, S. K. Lo, S. R. Targan et al., "Initial experience with wireless capsule enteroscopy in the diagnosis and management of inflammatory bowel disease," Clinical Gastroenterology and Hepatology, vol. 2, no. 1, pp. 31-40, 2004.
[40] A. S. Cheifetz, A. A. Kornbluth, P. Legnani et al., "The risk of retention of the capsule endoscope in patients with known or suspected Crohn's disease," The American Journal of Gastroenterology, vol. 101, no. 10, pp. 2218-2222, 2006.

[41] J. H. Cheon, Y.-S. Kim, I.-S. Lee et al., "Can we predict spontaneous capsule passage after retention? A nationwide study to evaluate the incidence and clinical outcomes of capsule retention," Endoscopy, vol. 39, no. 12, pp. 1046-1052, 2007.

[42] J. M. Herrerías, A. Caunedo, M. Rodríguez-Téllez, F. Pellicer, and J. M. Herrerías Jr., "Capsule endoscopy in patients with suspected Crohn's disease and negative endoscopy," Endoscopy, vol. 35, no. 7, pp. 564-568, 2003.

[43] C. Petruzziello, E. Calabrese, S. Onali et al., "Small bowel capsule endoscopy vs conventional techniques in patients with symptoms highly compatible with Crohn's disease," Journal of Crohn's and Colitis, vol. 5, no. 2, pp. 139-147, 2011.

[44] C. Spada, G. Spera, M. Riccioni et al., "A novel diagnostic tool for detecting functional patency of the small bowel: the given patency capsule," Endoscopy, vol. 37, no. 9, pp. 793-800, 2005.

[45] M. L. Boivin, H. Lochs, and W. A. Voderholzer, "Does passage of a patency capsule indicate small-bowel patency? A prospective clinical trial?” Endoscopy, vol. 37, no. 9, pp. 808-815, 2005.

[46] C. Signorelli, E. Rondonotti, F. Villa et al., "Use of the Given Patency System for the screening of patients at high risk for capsule retention," Digestive and Liver Disease, vol. 38, no. 5, pp. 326-330, 2006.

[47] C. Spada, S. K. Shah, M. E. Riccioni et al., "Video capsule endoscopy in patients with known or suspected small bowel stricture previously tested with the dissolving patency capsule," Journal of Clinical Gastroenterology, vol. 41, no. 6, pp. 576-582, 2007.

[48] R. Banerjee, P. Bhargav, P. Reddy et al., "Safety and efficacy of the M2A patency capsule for diagnosis of critical intestinal patency: results of a prospective clinical trial," Journal of Gastroenterology and Hepatology, vol. 22, no. 12, pp. 2060-2063, 2007.

[49] J. M. Herrerias, J. A. Leighton, G. Costamagna et al., "Agile patency system eliminates risk of capsule retention in patients with known intestinal strictures who undergo capsule endoscopy," Gastrointestinal Endoscopy, vol. 67, no. 6, pp. 902909, 2008.

[50] A. Yadav, R. I. Heigh, A. K. Hara et al., "Performance of the patency capsule compared with nonenteroclysis radiologic examinations in patients with known or suspected intestinal strictures," Gastrointestinal Endoscopy, vol. 74, no. 4, pp. 834839, 2011.

[51] S. A. C. van Tuyl, J. T. van Noorden, M. F. J. Stolk, and E. J. Kuipers, "Clinical consequences of videocapsule endoscopy in GI bleeding and Crohn's disease," Gastrointestinal Endoscopy, vol. 66, no. 6, pp. 1164-1170, 2007.

[52] C. Dussault, C. Gower-Rousseau, J. Salleron et al., "Small bowel capsule endoscopy for management of Crohn's disease: a retrospective tertiary care centre experience," Digestive and Liver Disease, vol. 45, no. 7, pp. 558-561, 2013.

[53] M. Flamant, C. Trang, O. Maillard et al., "The prevalence and outcome of jejunal lesions visualized by small bowel capsule endoscopy in Crohn's disease," Inflammatory Bowel Diseases, vol. 19, no. 7, pp. 1390-1396, 2013.

[54] M. D. Long, E. Barnes, K. Isaacs, D. Morgan, and H. H. Herfarth, "Impact of capsule endoscopy on management of inflammatory bowel disease: a single tertiary care center experience," Inflammatory Bowel Diseases, vol. 17, no. 9, pp. 1855-1862, 2011. 
[55] U. Kopylov, A. Nemeth, A. Koulaouzidis et al., "Small bowel capsule endoscopy in the management of established Crohn's disease: clinical impact, safety, and correlation with inflammatory biomarkers," Inflammatory Bowel Diseases, vol. 21, no. 1, pp. 93-100, 2015.

[56] R. Kalla, M. E. McAlindon, K. Drew, and R. Sidhu, "Clinical utility of capsule endoscopy in patients with Crohn's disease and inflammatory bowel disease unclassified," European Journal of Gastroenterology and Hepatology, vol. 25, no. 6, pp. 706-713, 2013.

[57] I. M. Gralnek, S. A. Cohen, H. Ephrath et al., "Small bowel capsule endoscopy impacts diagnosis and management of pediatric inflammatory bowel disease: a prospective study," Digestive Diseases and Sciences, vol. 57, no. 2, pp. 465-471, 2012.

[58] S. B. Min, M. Le-Carlson, N. Singh et al., "Video capsule endoscopy impacts decision making in pediatric IBD: a single tertiary care center experience," Inflammatory Bowel Diseases, vol. 19, no. 10, pp. 2139-2145, 2013.

[59] M. Tukey, D. Pleskow, P. Legnani, A. S. Cheifetz, and A. C. Moss, "The utility of capsule endoscopy in patients with suspected Crohn's disease," American Journal of Gastroenterology, vol. 104, no. 11, pp. 2734-2739, 2009.

[60] G. Van Assche, A. Dignass, J. Panes et al., “The second European evidence-based consensus on the diagnosis and management of Crohn's disease: definitions and diagnosis," Journal of Crohn's and Colitis, vol. 4, no. 1, pp. 7-27, 2010.

[61] M. Pennazio, C. Spada, R. Eliakim et al., "Small-bowel capsule endoscopy and device-assisted enteroscopy for diagnosis and treatment of small-bowel disorders: European Society of Gastrointestinal Endoscopy (ESGE) clinical guideline," Endoscopy, vol. 47, no. 4, pp. 352-376, 2015.

[62] I. M. Gralnek, R. Defranchis, E. Seidman, J. A. Leighton, P. Legnani, and B. S. Lewis, "Development of a capsule endoscopy scoring index for small bowel mucosal inflammatory change," Alimentary Pharmacology \& Therapeutics, vol. 27, no. 2, pp. 146$154,2008$.

[63] E. Gal, A. Geller, G. Fraser, Z. Levi, and Y. Niv, "Assessment and validation of the new capsule endoscopy Crohn's disease activity index (CECDAI)," Digestive Diseases and Sciences, vol. 53, no. 7, pp. 1933-1937, 2008.

[64] Y. Niv, S. Ilani, Z. Levi et al., "Validation of the Capsule Endoscopy Crohn's Disease Activity Index (CECDAI or Niv score): a multicenter prospective study," Endoscopy, vol. 44, no. 1, pp. 21-26, 2012.

[65] A. Koulaouzidis, S. Douglas, and J. N. Plevris, "Lewis score correlates more closely with fecal calprotectin than capsule endoscopy crohn's disease activity index," Digestive Diseases and Sciences, vol. 57, no. 4, pp. 987-993, 2012.

[66] T. Kono, N. Hida, K. Nogami et al., "Prospective postsurgical capsule endoscopy in patients with Crohn's disease," World Journal of Gastrointestinal Endoscopy, vol. 6, no. 3, pp. 88-98, 2014.

[67] M.-A. Denis, C. Reenaers, F. Fontaine, J. Belaïche, and E. Louis, "Assessment of endoscopic activity index and biological inflammatory markers in clinically active Crohn's disease with normal C-reactive protein serum level," Inflammatory Bowel Diseases, vol. 13, no. 9, pp. 1100-1105, 2007.

[68] T. Sipponen, H. Nuutinen, U. Turunen, and M. Färkkilä, "Endoscopic evaluation of Crohn's disease activity: comparison of the CDEIS and the SES-CD," Inflammatory Bowel Diseases, vol. 16, no. 12, pp. 2131-2136, 2010. 


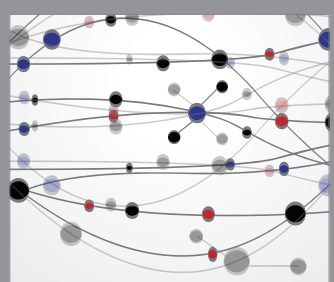

The Scientific World Journal
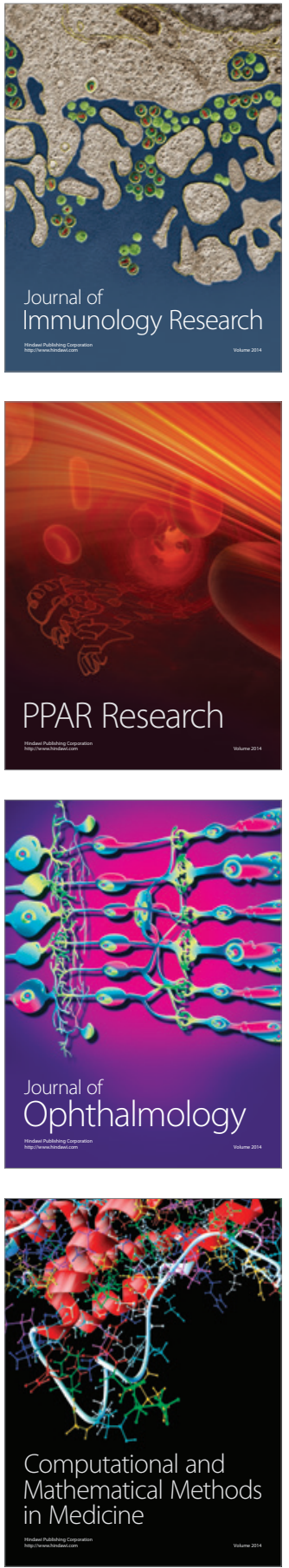

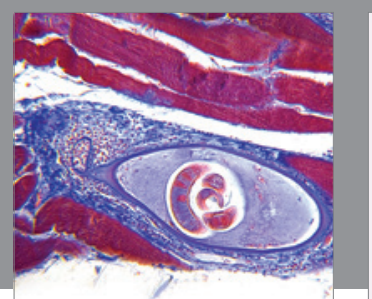

Gastroenterology Research and Practice

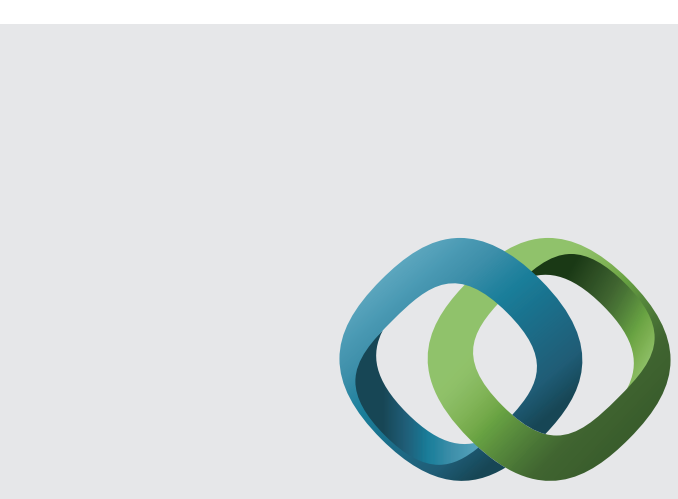

\section{Hindawi}

Submit your manuscripts at

http://www.hindawi.com
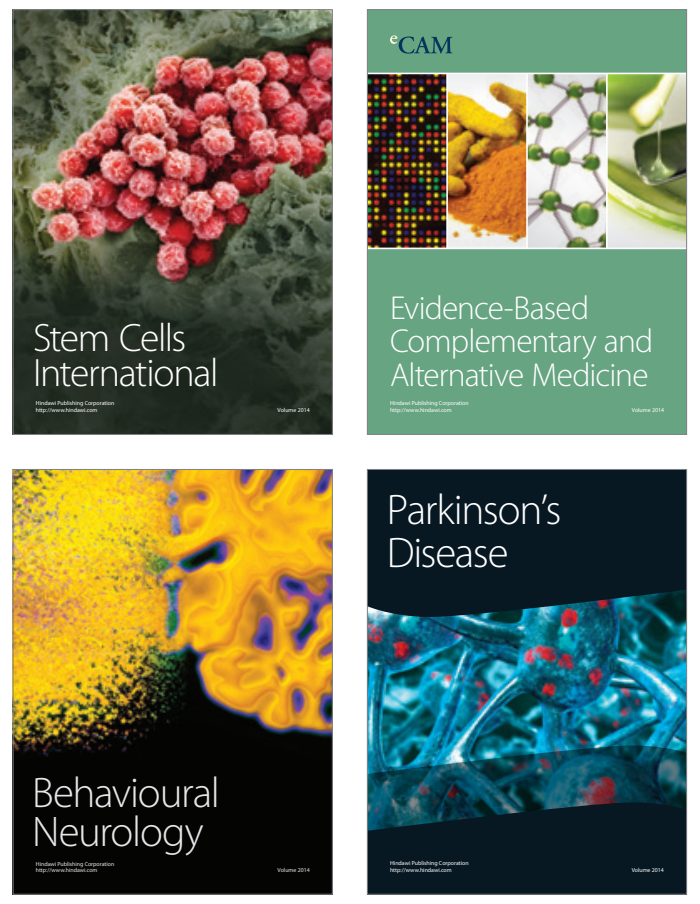
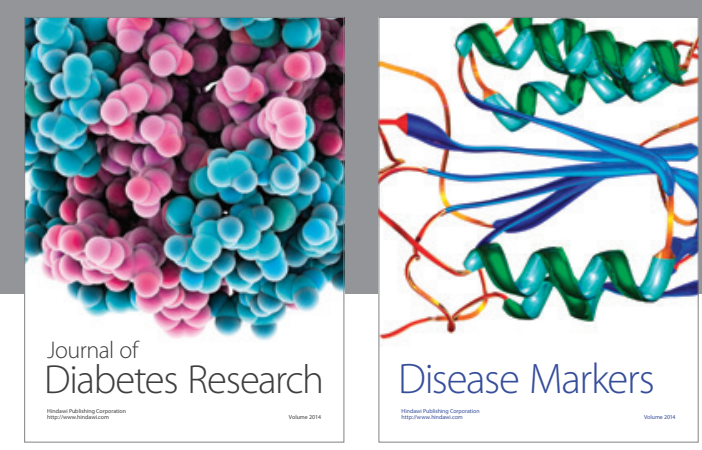

Disease Markers
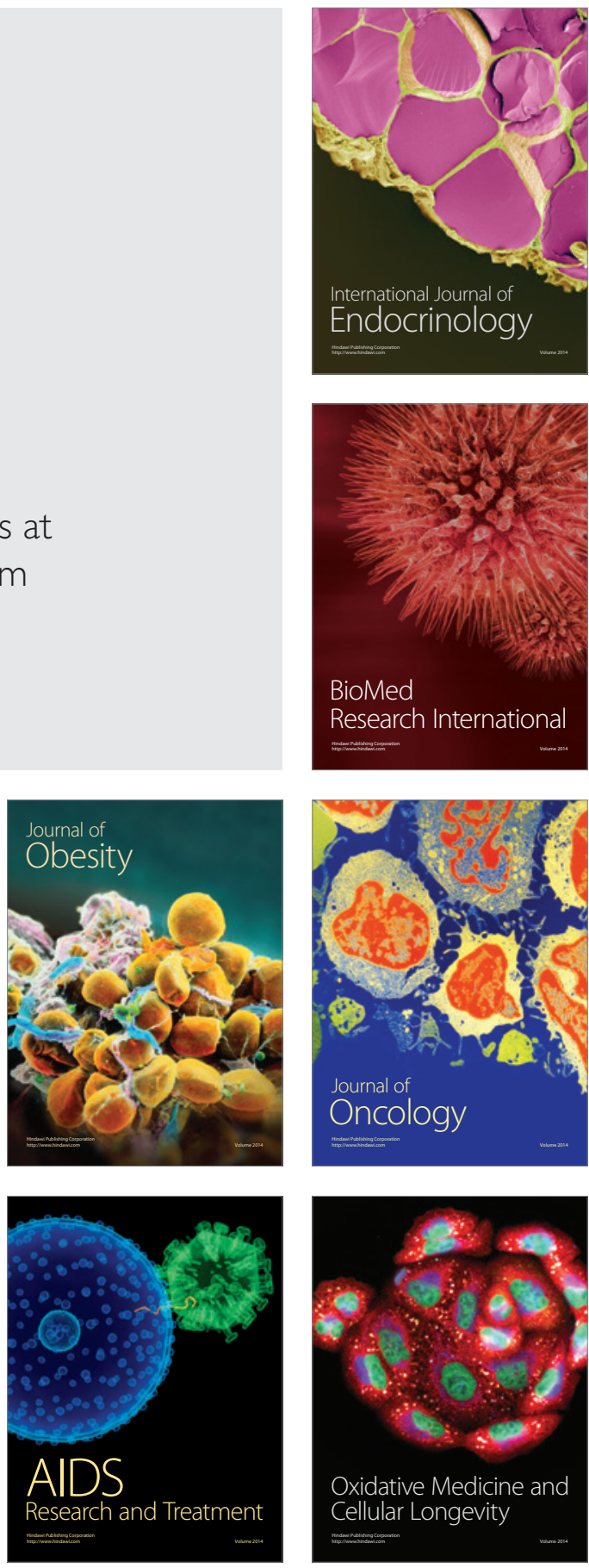